\title{
Revisiting the Comfort Parameters of ISO 7730: Measurement and Simulation
}

\author{
Mark B Luther ${ }^{1}$, Tarek MF Ahmed ${ }^{2}$ \\ ${ }^{1}$ School of Architecture \& Built Environment, Deakin University, Geelong, Australia \\ ${ }^{2}$ Department of Architecture \& Built Environment, Northumbria University, Newcastle, UK
}

\begin{abstract}
With the trends of comfort modelling moving more towards the application of Adaptive Models, the influences of several parameters as used in the traditional ISO7730 standard are therefore non-existent. The proposed work considers the conventional ISO 7730 standard as conservative in its calculation; however extremely useful, in cases where actual measurements of spaces are considered (ISO 7730, 1994). Measurements from a comfort cart built according to ASHRAE-55 standards (ANSI/ASHRAE 55, 2005) together with thermal imaging temperatures are combined. In doing so, an ISO 7730 thermal comfort assessment applying the CBE - ASHRAE 55-2004 Comfort Tool allows for changes in the environment to be examined for improved comfort (Huizenga, 2006; Tyler et al, 2017). Results for two cases in a severe Darwin climate yield an improved PPD by 2.5-2.7 times when implementing extremely lowenergy measures.
\end{abstract}

\section{Introduction}

\section{Comfort, Energy \& Building Design}

The existing literature, no doubt, presents the continuous challenge between thermal comfort with that of energy consumption (Barbadilla-Martín et al, 2018, Zampetti et al, 2018; Yun et al, 2016; Attia and Carlucci, 2015; Strengers, 2008). Alongside the multitude of research articles on thermal comfort, is perhaps the importance in recognition of the diversity on the subject itself. Meaning, that there are perhaps 'categories' into which the literature on comfort might be placed.

One of these research categories pertains to the acknowledgement and definition of the two fundamental models of comfort; namely

- the 'static' or 'rational' ISO 7730 (O. Fanger, 1970) standard; and

- the 'adaptive model' developed by Humphreys (1976), Auliciems (1997), or De Dear and Brager (1998) as well as others.

From these two different models we obtain the variables pertaining to each that produce an indicator of comfort. In the 'static' model it is useful to acknowledge that a thermal vote (a Predicted Mean Vote - PMV) or a Predicted Percentage Dissatisfied (PPD) is the outcome of six different variables; dry-bulb, mean radiant temperature, air-velocity, humidity, clothing level and metabolic rate.
The adaptive model has several authors from different periods in time, yet, all relating to the basic concept of obtaining a 'neutral temperature' using a predictor of external mean (monthly) temperature. These models all consider a particular building type which is naturally ventilated or provides the opportunity to be free running, passively conditioned and permits interaction with its users, allowing them to 'dress adaptively' to climatic seasons. They may even provide ceiling fans and window shading that occupants can adjust. These buildings are the opposite from sealed windows and a tightly regulated thermostatic control.

Nicol and Humphreys (2002) in discussing the adaptive model alongside the 'rational' (static) approach define the importance of good indoor climate not being only about comfort, but that it will determine its energy consumption and ultimately sustainability.

Interestingly, Nicol and Humphreys (2002) claim that when the 'rational' model indices are used to predict thermal comfort of subjects measured in the field, they are found to be no better than simpler indices such as temperature alone. Consequently, they claim that the 'comfort temperature' is a result of the interaction between the subjects and the building or environment they occupy.

While the authors of this paper do not dispute the above and are in favour of 'adaptive model' buildings there remains an argument in support of utilising the 'rational' (or static) model. Predictors of comfort are not necessarily the direct causes or explanation of the result (Jones, 2002). In other words, several other parameters may influence the comfort outcome often represented as a 'neutral temperature'. While a neutral temperature could be observed as a comfort result, in the adaptive model, it does not necessarily explain the possible causes of this result.

What never really seems to be explained by the adaptive models are the numerical and quantitative influences of interior variables that can influence the 'comfort temperature'. Several reports mention air-velocity and possibly humidity in regard to the Operative Temperature or the Standard Effective Temperature (SET) (Yun et al, 2016). For the most part however, mean radiant temperature is rarely mentioned in these analyses. While it appears that these 'rational' indices are not required (by the experts) to determine the 'comfort temperature' it is argued here that they could assist in influencing building design to make a more responsive building. In other 
words, they offer explicit measures that can change comfort. Nicol and Humphreys (2002) do state that the 'range of comfort' predicted by these 'rational' methods is far wider than calculated. This is pleasing information, since what is proposed here (in this paper), is to utilise these 'rational' parameters in order to approach a lower Predicted Percentage Dissatisfied (PPD) for a severe indoor climate.

While it may be interesting to note that the outdoor climate is a significant independent variable to the indoor 'comfort temperature' prediction, as a building designer or service consultant, we have no control over this variable. However, as designers or consultants we can respond to the average or extreme results of this variable through the selection of our building materials and their design of envelope apertures. This last point brings us to acknowledging possibly two other categories related to comfort research in addition to the first category which was pertaining to establishing the two models and the buildings they apply to.

The second category is the application of the comfort models into controlling mechanical equipment (HVAC) and/or building operation. There are a selective few who have explored and reported such information. BarbahillaMartin et al (2018) report the application of an adaptive model of comfort applied to the thermostatic control in a mixed-mode office building. The neutral set-point is based upon a mean monthly external temperature or utilises a running average over the past several weeks. Findings indicate that there are up to $30 \%$ saving for cooling periods and about $12 \%$ during heating periods with minor (if any) sacrifice for comfort. Another study by Tanabe et al (2013) from Japan explored the productivity levels and energy savings under mandatory electricity legislation after the Great East Japan tsunami. Field studies were conducted in five office buildings measuring and assessing occupant thermal sensation votes. The results related to thermal comfort tolerance levels in regard to energy savings.

Lastly, we introduce a third category, which may in part be mentioned among the first two categories of comfort research, namely, the design of the building itself. It is evident that the literature establishes the differences between a 'static', mixed mode, and naturally ventilated building. In fact, Kaltz and Pfafferott (2010) claim that there are five different classifications of buildings that respond and operate differently to achieve thermal comfort. These are; (i) fully air-conditioned (ii) mixedmode air-conditioned (iii) low-energy with mechanical cooling (iv) low energy with passive cooling and (v) buildings without cooling. The authors here would consider that buildings ii - iv would be called variations on hybrid-controlled buildings. In fact, the mechanism of conditioning, whether natural air-flow ventilation, ceiling fan driven, or convectively conditioned air flow is never clearly mentioned nor are radiative system; ceiling, floors or consoles. It would appear that there are a multitude of possibilities and that these would determine occupant control (or lack of it) and comfort.
Analysing the Building for Improvements to Comfort

From the literature it can be ascertained that buildings that offer interaction through their design and/or service systems are more likely to provide better 'comfort temperature' possibilities or attainment of such. In other words, provisions in the building itself, to provide for changes in air temperature, air movement, relative humidity, and mean radiant temperature are more likely to achieve a 'comfort temperature' accepted by occupants. Furthermore, buildings that allow occupants to adapt in terms of clothing levels and provide some interaction with the building parameters are even more likely to achieve this 'comfort temperature'.

Therefore, it is practical in the design or improved analysis of building comfort to consider a model that allows for a multitude of variables to be considered, studied and altered in the pursuit of comfort. Hence, the application of the 'static' model (ISO 7730, 1994) is revisited and applied in this paper to actual measurements of residential interiors in the severe climate of Darwin.

We turn to the CBE ASHRAE Thermal Comfort Tool, which allows for specific time periods of discomfort from real measurements to be analysed (Tyler et al, 2017). It is fortunate that the tool also accounts for a localised mean radiant temperature for a particular room with known (or specified) interior surface temperatures of walls, windows, floor and ceiling to be calculated. It was noticed that this tool suited our real time-based measurements taken with a standardised Comfort Cart (see Figure 1).

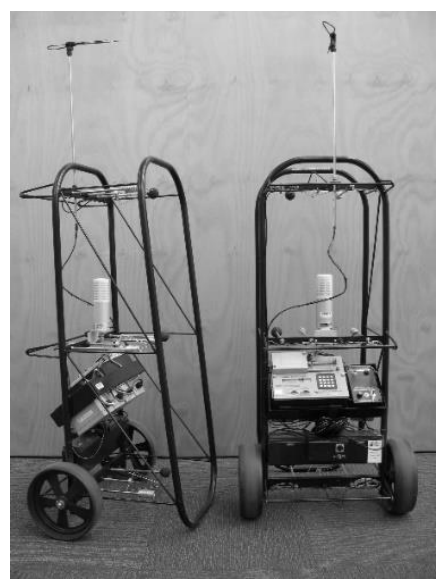

Figure 1: A Comfort Cart according to ANSI/ASHRAE Standard 55-2004

The comfort cart establishes the measurement of drybulb temperature, air-velocity and globe temperature taken at $100 \mathrm{~mm}, 600 \mathrm{~mm}, 1100 \mathrm{~mm}$ and also $1700 \mathrm{~mm}$ heights. At the $600 \mathrm{~mm}$ level humidity and $\mathrm{CO} 2$ are measured. These measurements allow for a mean radiant temperature to be calculated at the 100,600 and $1100 \mathrm{~mm}$ heights. Furthermore, a Predicted Mean Vote (PMV) and a Predicted Percent Dissatisfied (PPD) can be calculated at each of these levels. In summary, the Thermal Comfort Cart exhibits a measurement of PPD, PMV and Mean Radiant Temperature for the location that it is placed. In particular, the mean radiant temperature is a result of all 
the surface temperatures in the room influencing its temperature at the comfort cart location.

An NEC Avio high level thermal imaging camera, as shown in Figure 2, was applied to the imaging of several different rooms in different houses during a performance measurement investigation in Darwin, Australia. This camera has the capability of producing photo imaging measurements every 15 minutes. The results produced a logging of the surface temperatures of the space while at the same moment measurements were recorded by the comfort cart.

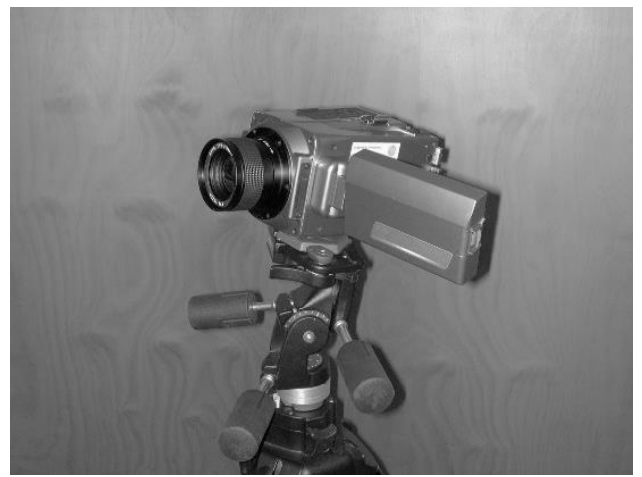

Figure 2: NEC - Avio Thermal Imaging Camera

The serendipitous discovery of the presented research (12 years later) combines both the measurement of the thermal imaging camera and the comfort cart results of PPD, PMV and mean radiant temperature, together with that of the ASHRAE 55 Comfort Tool. The procedure for combining these measured results and the simulation tool is outlined here:

- The ASHRAE 55 Comfort Tool is applied, entering the known measured values of dry-bulb temperature, air-velocity, and relative humidity measured by the Comfort Cart.

- A CLO (clothing) value and MET (metabolic rate) have already been established prior to this analysis and have been entered in the ASHRAE 55 Comfort Tool program.

- Given that the surface temperatures are known through the measurement of the thermal imaging camera results they can now be applied to the Mean Radiant Temperature program within the ASHRAE 55 Comfort Tool.

- The entire room dimensions, with window sizes and the Comfort Cart location (essentially the location of an occupant in the room) can be entered into the ASHRAE 55 Comfort Tool.

- Next, the calculated result of Mean Radiant Temperature from the measurements of the Comfort Cart can now be compared with the ASHRAE 55 Comfort Tool simulated result.

- Refinements are made in slight temperature adjustments to various surfaces in the ASHRAE Comfort Tool until they virtually match the measured comfort cart result as well as the cart's calculated PPD.
- In completion of this process we now have a result of the PPD, PMV and mean radiant temperature that are both in agreement. In other words, the results of the ASHRAE 55 Comfort Tool match those that were measured in the space.

The above process demonstrates a combination of measurement and simulation uniting to provide a useful forthcoming analysis of thermal comfort alterations for the particular space. The ASHRAE 55 Comfort Tool can now be considered as a vehicle to examine various 'What If' scenarios. In particular we can begin to ask what could building surfaces, proper window design, air movement and special conditioning systems provide towards the improvement of comfort.

The fact that the ISO 7730 comfort model has several variables that the building could be held responsible for is fortuitous. As architects and building designers we can begin to ask what the building design or its conditioning systems could do to provide:

- $\quad$ an increase or decrease in air movement?

- a reduction or increase in interior facing surface temperatures?

- humidity level control?

- a uniform air temperature distribution without stratification?

These are all valid questions in the pursuit of improving thermal comfort. 'Ask not what you can do for your building, but what your building can do for you' as a matter of formulating the argument in opposition to what most of our research on comfort has been pursuing. It is high time that our buildings start providing the design and service systems that provide for our comfort and amenity that we expect, as we do in other products we acquire - for instance - our automobiles. Furthermore, our research needs to explore and report the services and systems that can accomplish such, at minimal expense to our environment.

\section{Methods}

This research utilises real measurements together with a well-known thermal comfort tool CBE - ASHRAE-55. Through the application of a thermal comfort cart as well as thermal imaging a comprehensive set of data is accomplished for a particular interior space. The comfort cart measurements are processed to yield the ISO-7730 comfort indices. The ISO standard calculation yields the Predicted Percentage Dissatisfied (PPD) and other parameters such as MRT are result of this calculation. These results serve as the guide to validate and fine-tune the ASHRAE 55 Comfort Tool inputs until the simulation outputs match the measured result.

The ASHRAE-55 Comfort Tool has a sub-routine for the calculation of mean radiant temperature of a space. This routine allows for the measured inputs of wall and glass surface temperatures to be entered into the simulation tool, providing a total room mean radiant temperature result. This simulated result is once again compared with the ISO-7730 measured output from the comfort cart. 
The innovation now rests in applying the comfort tool to achieve informed decision-making that can improve comfort conditions. For example, shading the glass from direct heat gain, thereby reducing the surface temperature substantially. Other solutions may consider applying radiant cooling systems for the ceiling and floor that will reduce the overall mean radiant temperature, or a change in air velocity through a ceiling fan, or a mechanism that reduces humidity levels, etc.

\section{Results}

\section{Comfort Provision Process}

The process, as described above, is now applied to several rooms of two different houses measured in in Darwin during the month of February. This is time of year is

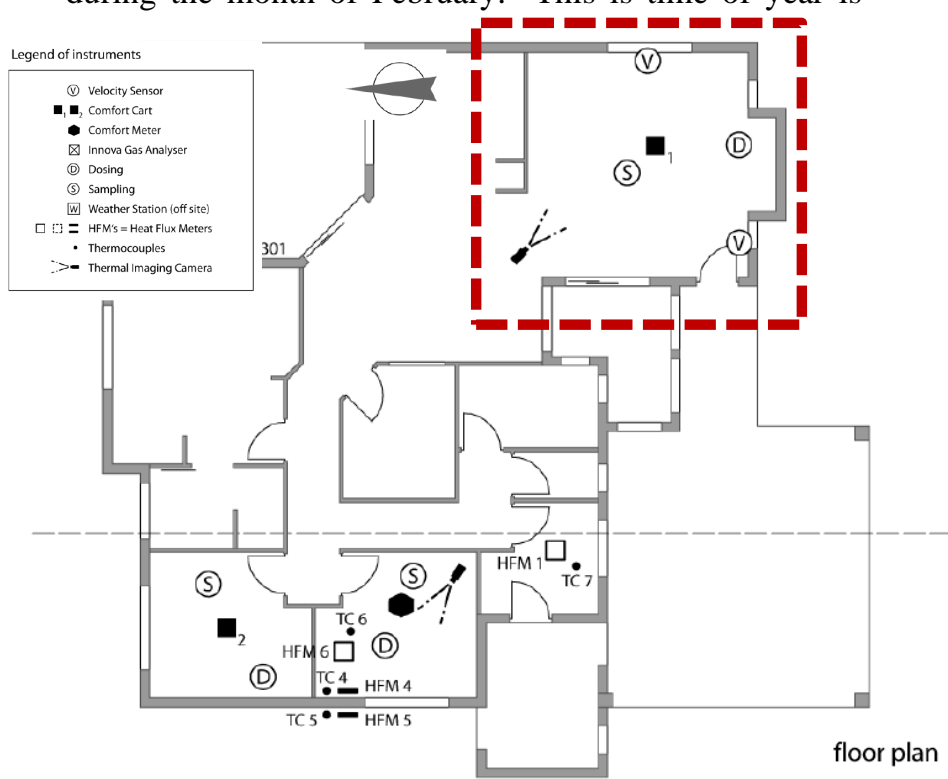

Figure 3: Instrumentation and Measurement Points of the Blockhouse - Darwin

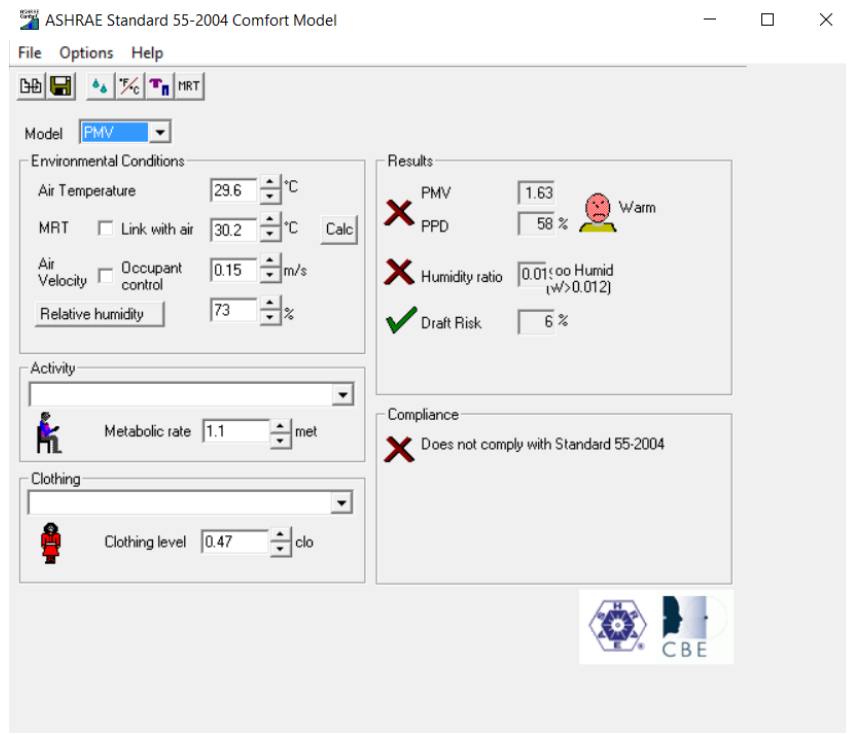

Figure 5: The ASHRAE 55 Comfort Tool (Huizenga, 2006) considered the most severe and difficult in terms of achieving comfort in the building.

- The Block House Living Room

Figure 3 below shows the floor plan of the Blockhouse which consists of a newer construction method introduced into Darwin residential building. A result of the thermal imaging during the most severe period in terms of thermal comfort is shown in Figure 4. The ASHARE 55 Comfort Tool is applied here (Figure 5 and Figure 6) to first replicate the measured results. Thereafter we provide a stepped process to adjusting various room parameters that affect the result of comfort. Table 1 provides the comfort results (PPD) of changes to various parameters in stages, as described below the table.

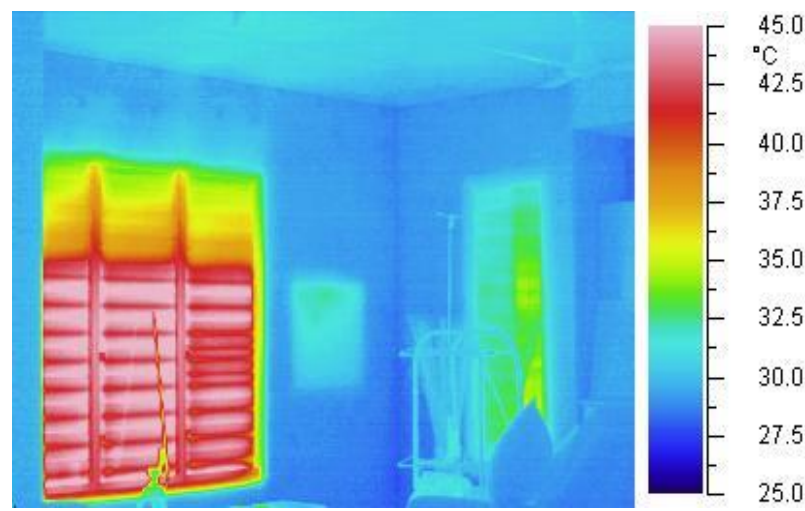

Figure 4: Thermal Imaging of Surface Temperatures in the Blockhouse - Living Room 9:15a.m.

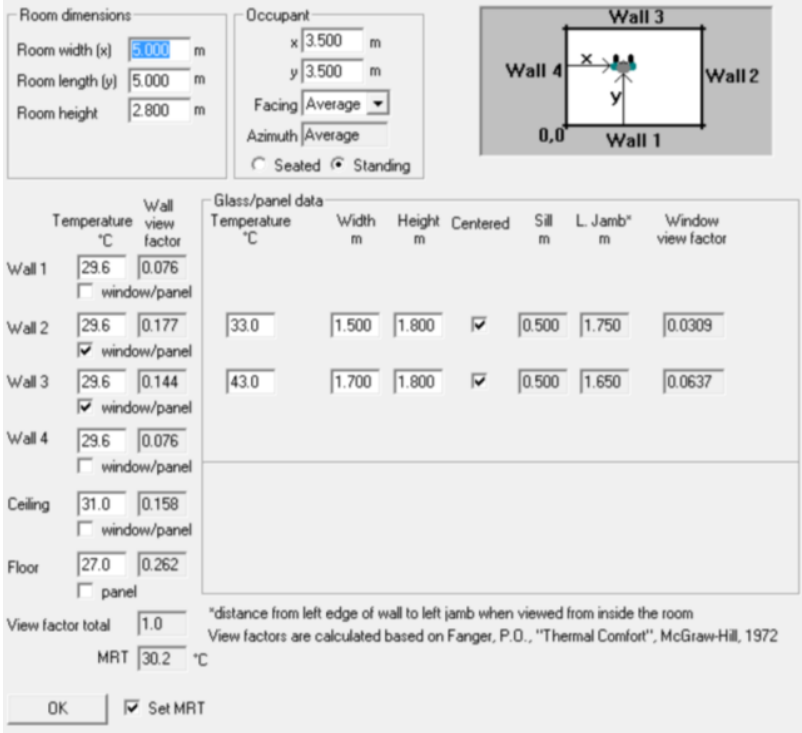

Figure 6: Mean Radiant Temperature module of the ASHRAE 55 Tool (Huizenga, 2006) 
Table 1: The Blockhouse Living Room-Original Comfort Case \& Improvements

\begin{tabular}{|c|c|c|c|c|c|c|c|c|c|c|}
\hline Case & PPD & $\mathbf{D B}_{\text {(air) }}$ & MRT & $\begin{array}{l}\text { Relative } \\
\text { Humidity }\end{array}$ & $\begin{array}{r}\text { GI } \\
\text { Temp }\end{array}$ & $\begin{array}{l}\text { SS } \\
\text { atures }\end{array}$ & $\begin{array}{c}\text { Air } \\
\text { Velocity }\end{array}$ & $\begin{array}{l}\text { Ceiling } \\
\text { Temp }\end{array}$ & $\begin{array}{l}\text { Floor } \\
\text { Temp }\end{array}$ & $\begin{array}{l}\text { Wall } \\
\text { Temp }\end{array}$ \\
\hline I & $58 \%$ & $29.6^{\circ} \mathrm{C}$ & $30.2^{\circ} \mathrm{C}$ & $73.0 \%$ & $43^{\circ} \mathrm{C}$ & $33^{\circ} \mathrm{C}$ & $0.15 \mathrm{~m} / \mathrm{s}$ & $31.0^{\circ} \mathrm{C}$ & $27.0^{\circ} \mathrm{C}$ & $29.6^{\circ} \mathrm{C}$ \\
\hline A-1 & $47 \%$ & $29.6^{\circ} \mathrm{C}$ & $28.9^{\circ} \mathrm{C}$ & " & $43^{\circ} \mathrm{C}$ & $33^{\circ} \mathrm{C}$ & $0.15 \mathrm{~m} / \mathrm{s}$ & $26.0^{\circ} \mathrm{C}$ & $26.0^{\circ} \mathrm{C}$ & $26.0^{\circ} \mathrm{C}$ \\
\hline B-1 & $29 \%$ & $28.6^{\circ} \mathrm{C}$ & $28.0^{\circ} \mathrm{C}$ & “ & $32.0^{\circ} \mathrm{C}$ & $32.0^{\circ} \mathrm{C}$ & $0.15 \mathrm{~m} / \mathrm{s}$ & $26.0^{\circ} \mathrm{C}$ & $26.0^{\circ} \mathrm{C}$ & $26.0^{\circ} \mathrm{C}$ \\
\hline $\mathrm{C}-1$ & $23 \%$ & $28.6^{\circ} \mathrm{C}$ & $28.0^{\circ} \mathrm{C}$ & “ & $32.0^{\circ} \mathrm{C}$ & $32.0^{\circ} \mathrm{C}$ & $0.25 \mathrm{~m} / \mathrm{s}$ & $26.0^{\circ} \mathrm{C}$ & $26.0^{\circ} \mathrm{C}$ & $26.0^{\circ} \mathrm{C}$ \\
\hline
\end{tabular}

= Original Measured Case: ASHRAE 55 Comfort Tool Simulation calibrated to Comfort Cart measurements.

Note: All other cases are simulations - ONLY calculated through the ASHRAE 55 Comfort Tool.

A-I: The floor, ceiling and interior Wall-1 surfaces are hydronically cooled to $26.0^{\circ} \mathrm{C}$ which is above the dewpoint during this period.

B-I: The glass is shaded, thereby reduced to $32^{\circ} \mathrm{C}$ and air temperature is reduced by $1{ }^{\circ} \mathrm{C}$ (to $28.6^{\circ} \mathrm{C}$ ) considering convective heat transfer processes among the cooled room surfaces.

C-I: A ceiling fan is applied to increase the air velocity (marginally) to $0.25 \mathrm{~m} / \mathrm{s}$.

The result is an improvement in PPD by 2.5 times achieved through extremely low energy inputs.

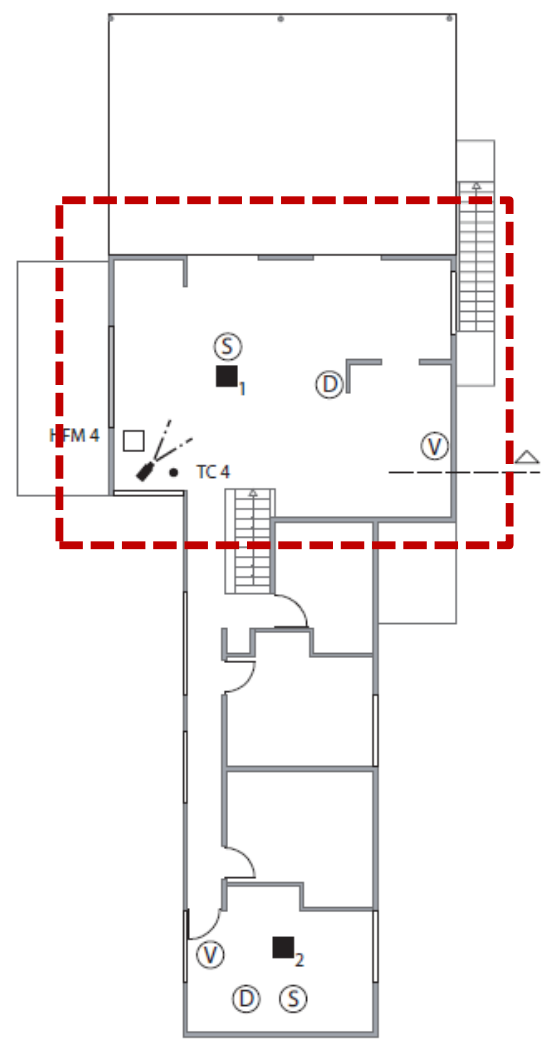

upper floor
It is important to realise that adaptive models of comfort would be far more lenient than what is proposed here. In other words, the likelihood of comfort would undoubtedly be accepted by more than $80 \%$ of occupants clothed and accustomed to this Darwin climatic condition.

In a second case, for a different house, with an elevated floor level, typical for houses designed in Darwin, a severe time period is observed. Figure 7 shows the thermal floor plan and a resulting thermal imaging. As before in the Blockhouse example, the process of calibrating both the mean radiant temperature results with those of the comfort cart through the ASHRAE 55 Comfort Tool is accomplished. We present the PPD (predicted percentage dissatisfied) results from a staged process of interior conditioning improvements in Table 2.
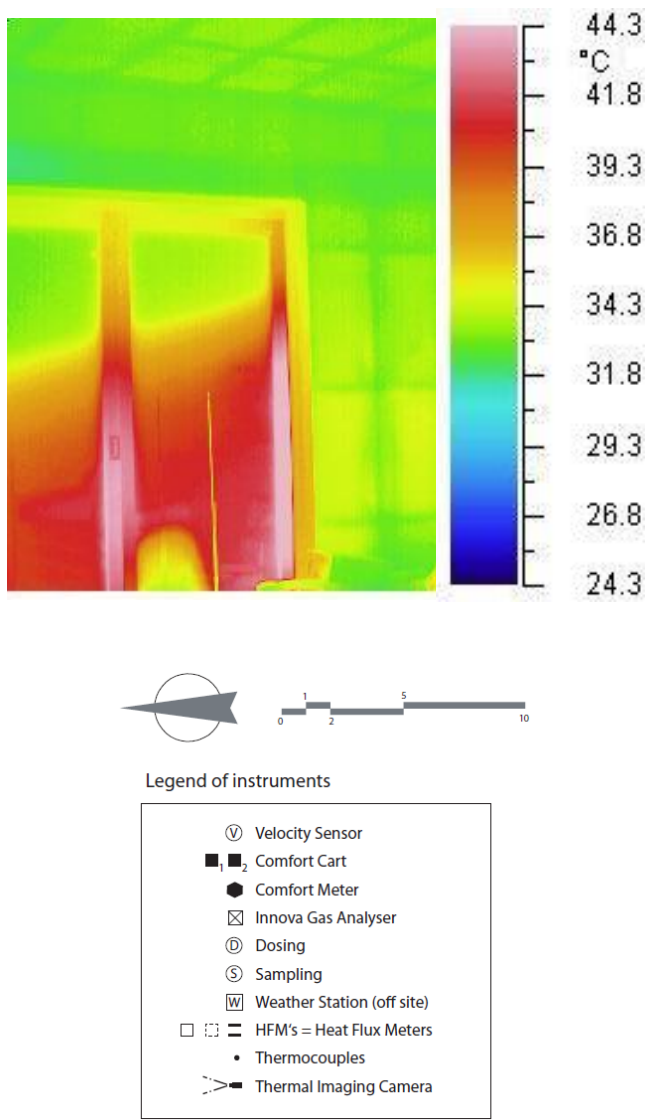

Figure 7: Floor Plan and Thermal Imaging Results of the Elevated House 
Table 2: The Elevated House - Original Case \& Improvements

\begin{tabular}{|c|c|c|c|c|c|c|c|c|c|}
\hline Case & PPD & $\mathbf{D B}_{\text {(air) }}$ & MRT & $\begin{array}{c}\text { Relative } \\
\text { Humidity }\end{array}$ & $\begin{array}{c}\text { GLASS } \\
\text { Temperature }\end{array}$ & $\begin{array}{c}\text { Air } \\
\text { Velocity }\end{array}$ & $\begin{array}{c}\text { Ceiling } \\
\text { Temp }\end{array}$ & $\begin{array}{c}\text { Floor } \\
\text { Temp }\end{array}$ & $\begin{array}{c}\text { Wall } \\
\text { Temp }\end{array}$ \\
\hline II & $94 \%$ & $32.5^{\circ} \mathrm{C}$ & $32.7^{\circ} \mathrm{C}$ & $61 \%$ & $40.0^{\circ} \mathrm{C}$ & $0.2 \mathrm{~m} / \mathrm{s}$ & $33.5^{\circ} \mathrm{C}$ & $31.0^{\circ} \mathrm{C}$ & $32.5^{\circ} \mathrm{C}$ \\
\hline $\mathrm{A}-2$ & $71 \%$ & $32.5^{\circ} \mathrm{C}$ & $28.4^{\circ} \mathrm{C}$ & $61 \%$ & $40.0^{\circ} \mathrm{C}$ & $0.2 \mathrm{~m} / \mathrm{s}$ & $\mathbf{2 4 . 0 ^ { \circ } \mathbf { C }}$ & $\mathbf{2 4 . 0 ^ { \circ } \mathrm { C }}$ & $32.5^{\circ} \mathrm{C}$ \\
\hline $\mathrm{B}-2$ & $68 \%$ & $32.5^{\circ} \mathrm{C}$ & $28.0^{\circ} \mathrm{C}$ & $61 \%$ & $\mathbf{3 2 . 0} 0^{\circ} \mathbf{C}$ & $0.2 \mathrm{~m} / \mathrm{s}$ & $24.0^{\circ} \mathrm{C}$ & $24.0^{\circ} \mathrm{C}$ & $32.5^{\circ} \mathrm{C}$ \\
\hline $\mathrm{C}-2$ & $43 \%$ & $\mathbf{3 0 . 5}^{\circ} \mathbf{C}$ & $28.0^{\circ} \mathrm{C}$ & $61 \%$ & $32.0^{\circ} \mathrm{C}$ & $0.2 \mathrm{~m} / \mathrm{s}$ & $24.0^{\circ} \mathrm{C}$ & $24.0^{\circ} \mathrm{C}$ & $32.5^{\circ} \mathrm{C}$ \\
\hline $\mathrm{D}-2$ & $35 \%$ & $30.5^{\circ} \mathrm{C}$ & $28.0^{\circ} \mathrm{C}$ & $61 \%$ & $32.0^{\circ} \mathrm{C}$ & $\mathbf{0 . 3} \mathbf{m} / \mathbf{s}$ & $24.0^{\circ} \mathrm{C}$ & $24.0^{\circ} \mathrm{C}$ & $\mathbf{3 1 . 0}^{\circ} \mathbf{C}$ \\
\hline
\end{tabular}

= Original Measured Case: ASHRAE 55 Comfort Tool Simulation calibrated to Comfort Cart measurement.

Note: All other cases are simulations - ONLY calculated through the ASHRAE 55 Comfort Tool.

A-II: The floor and ceiling are hydronically cooled to $24.0^{\circ} \mathrm{C}$ which is above the dewpoint in this case.

B-II: The glass is shaded and reduced to $32^{\circ} \mathrm{C}$.

C-II: Convective heat transfer among the room surfaces reduces air temperature by $2.0^{\circ} \mathrm{C}$ down to $30.5^{\circ} \mathrm{C}$. This is reasonable to assume considering the large ceiling and floor areas making up the volume of this space.

D-II: Ceiling fan applied to increase the air velocity (marginally) to $0.3 \mathrm{~m} / \mathrm{s}$.

The result is an improvement of PPD by 2.7 times achieved through extremely low energy inputs.

While the PPD remains relatively high at $35 \%$ we believe that this is still a very conservative figure, meaning that the adaptive model would be substantially lower in its PPD result. Furthermore, this room experiences this extreme temperature for approximately 30-45 minutes. Other periods of the day are far less severe than the one dealt with here.

Results indicate that the application of radiant systems in a hot humid climate are effective in improving comfort. In particular, the idea of cooling interior ceiling, floor and possibly wall surfaces through hydronic systems is explored (Tye-Gingras and Gosselin, 2012). The introduction of lightweight capillary hydronic matts (German and Japanese manufacturers) integrated with gypsum drywall construction or tiled floors as a possible cooling solution is proposed. Surface temperature levels that are between $24-26^{\circ} \mathrm{C}$ and well above dew point (2$3 \circ \mathrm{C}$ ) indicate promising results for improved comfort in these environments. Furthermore, radiative conditioning, for leaky and poorly insulated houses, offers an improved energy cost benefit when compared to convective air conditioning systems.

\section{Discussion and Conclusion}

There has been an increasing effort in research, investigating the measurement and sensors applied to evaluating interior environments. Zampetti et al (2018) have developed a 'Comfort Eye' IR sensor that can provide for the Mean Radiant Temperature of an environment. They claim that the non-homogenous thermal comfort component can be identified through this mean radiant temperature measurement which is far superior to conventional thermostatic control. Other researchers have been investigating systems for radiant ceiling cooling inclusive of the new capillary type (Catalina et al 2009; Xie et al 2016). This research demonstrates a possible lightweight and very responsive radiant panelised system for room surfaces (floors, walls and ceiling). The numerical evaluation on the comfort of these radiant systems is gaining research interest as indicated in the work by Mustakallio et al (2016), TyeGingras and Gosselin (2012), and Miriel et al (2002).

One of the assumptions made in this (our) paper is the degree and/or contribution that a radiant cooled surface can provide in terms of convention to changing the drybulb temperature within a space. In other words, at this point in time there was no numerical calculation to determining the dry-bulb parameter change as applied to the ASHRAE-55 Comfort Tool. Further work is expected to take place in this area of the problem. Others such as Causone et al (2009) have looked into this problem. It is anticipated that our research work will investigate this matter empirically through full-scale experimental projects as we are primarily interested in the introduction of hydronically radiant cooled surfaces into building spaces.

What our work has indicated here, we believe, is a promising method and stepped process towards analysing and potentially improving severe and difficult to control environments in the tropics. This investigation has provided a gateway to other related and extended research on a very important topic. We have begun to realise the importance of real spatial measurement alongside evaluation tools such as the ASHRAE 55 Thermal Comfort Tool. This project has launched interest in several new avenues as related to comfort research, its measurement and tools, as well as its service systems that sense and provide conditioning for it.

\section{References}

A.C. van der Linden, A.C. Boerstra, A.k. (2006). Adaptive temperature limits: A new guideline in The Netherlands: A new approach for the assessment of building performance with respect to thermal indoor climate, Energy and Building 38(1), 8-17.

ANSI/ASHRAE 55. (2005). American Society of Heating, Refrigerating and Air-Conditioning Engineers. Thermal Environmental Conditions for Human Occupancy.

Attia, S. and Carlucci, S. (2015). Impact of different thermal comfort models on zero energy residential 
buildings in hot climate. Energy and Buildings 102, 117-128.

Auliciems, A., \& Szokolay, S.V. (1997). Thermal Comfort: Design Tools and Techniques. Proceedings from PLEA1999: Passive and Low energy Architecture Conference. Brisbane (Australia), 22-24 September 1997.

Barbadilla-Martín, E., Martín, J.G., Lissén, J.M., Ramos, J.S. (2018). Assessment of thermal comfort and energy savings in a field study on adaptive comfort with application for mixed mode offices, Energy and Buildings 167, 281-289.

Catalina, T., Virgone, J., Kuznik, F. (2009). Evaluation of thermal comfort using combined CFD and experimentation study in a test room equipped with a cooling ceiling, Building and Environment 44(8), 1740-1750.

Causone, F., Corgnati, S.P., Filippi, M. Olesen, B.W. (2009). Experimental evaluation of heat transfer coefficients between radiant ceiling and room, Energy and Buildings 41(6), 622-628.

De Dear, R.J., \& Brager, G.S., (1998). Developing an adaptive model of thermal comfort and preference. Proceedings of the 1998 ASHRAE Winter Meeting, ASHRAE. SanFrancisco, CA(USA), 145-167.

Huizenga, C. (2006). Revisions to the ASHRAE thermal comfort tool to maintain consistency with Standard 55-2004 (ASHRAE 1332-RP), Centre for the Built Environment, University of California.

Humphreys, M.A. and Nicol, J.F. (2002). The validitiy of ISO-PMV for prediciting comfort votes in every-day thermal environments, Energy and Buildings 34, 667684.

ISO 7730; International Organization for Standards (1994). Determination of the PMV and PPD Indices and Specification of the Conditions for Thermal Comfort, Moderate Thermal Environments (ISO 7730).

Jones, B.W. (2002). Capabilities and limitations of thermal models for use in thermal comfort standards, Energy and Buildings 34, 653-659.

Kalz, D.E. and Pfafferott, J. (2010). Comparative evaluation of natural ventilated and mechanical cooled non-residential buildings in Germany: thermal comfort in summer. Proceedings from Adapting to
Change: New Thinking on Comfort Conference. Windsor Great Park (UK), 9-11 April 2011.

Miriel, J. Serres, L. Trombe, A. (2002). Radiant ceiling panel heating-cooling systems: experimental and simulated study of the performances, thermal comfort and energy consumptions, Applied Thermal Engineering 22(16), 1861-1873.

Mustakallio, P. Bolashikov, Z. Kostov, K. Melikov, A. Kosonen, R. (2016). Thermal environment in simulated offices with convective and radiant cooling systems under cooling (summer) mode of operation, Building and Environment 100, 82-91.

Nicol, J.F., Humphreys, M.A. (2002) Adaptive thermal comfort and sustainable thermal standards for buildings, Energy and Buildings 166(6), 563-572.

Tanabe, S., Iwahashi, Y., Tshushima, S., Nishihara, N. (2013). Thermal comfort and productivity in offices under mandatory electricity savings after the Great East Japan earthquake, Architecture Science Review 56(1), 4-13.

Tye-Gingras, M. and Gosselin, L. (2012). Comfort and energy consumption of hydronic heating radiant ceilings and walls based on CFD analysis, Building and Environment 44(8),1-13.

Tyler, H., Stefano, S., Alberto, P., Toby, C., Dustin, M., and Kyle, S. (2017). CBE Thermal Comfort Tool. Center for the Built Environment, University of California Berkeley, http://comfort.cbe.berkeley.edu/

Xie, D. Wang, Y. Wang, H. Mo, S. Liao, M. (2016). Numerical analysis of temperature non-uniformity and cooling capacity for capillary ceiling radiant cooling panel, Renewable Energy 87(3), 1154-1161.

Strengers, Y. (2008). Comfort expectations: the impact of demand-management strategies in Australia, Building Research \& Information 36(4), 381-391.

Yun, G.Y., Lee, J.H., Steemers, K. (2016). Extending the applicability of the adaptive comfort model to the control of air-conditioning systems, Building and Environment 105, 13-23.

Zampetti, L., Arnesanon, M., Revel, G.M. (2018). Experimental testing of a system for the energyefficient sub-zonal heating management in indoor environments based on PMV, Energy and Buildings $166,229-238$. 